\title{
NOTE
}

\section{Prediction of grout penetration in fractured rocks by numerical simulation}

\author{
M.J. Yang, Z.Q. Yue, P.K.K. Lee, B. Su, and L.G. Tham
}

\begin{abstract}
As fractures in rock significantly reduce the strength as well as the stiffness of the rock mass, grouting may be required to improve the performance of the rock mass in engineering or mining projects. During grouting, mortar of cement or other materials is injected into the rock mass so that the fractures can be filled up and the rock mass can act as an integral unit. Unlike water, grouts are usually viscous and behave as non-Newtonian fluids. Therefore, the equations describing the flow of grout are more complicated and the solutions are quite difficult to obtain. The problem is further aggravated by the fact that the fractures are mostly randomly distributed, and it is rarely possible to accurately define the fractures and the distribution patterns. In this paper, a numerical model is proposed for analyzing the grouting process. The model is based on the stochastic approach, and it can provide the depth of penetration and the fluid pressure due to the flow of grout, which is modeled as a Bingham fluid, in the fractured rock mass. Parametric studies have been carried out to investigate the effects of various factors on the depth of penetration, and a regression formula is developed for calculating the penetration depth. Experiments have been carried out and their results are used to validate the present method.
\end{abstract}

Key words: stochastic fractures, fractured rock mass, grout flow, grout penetration.

Résumé : Comme les fractures dans la roche diminuent de façon significative la résistance de même que la rigidiré du massif rocheux, de l'injection peut être requise pour améliorer la performance du massif rocheux dans les projets d'ingénieurs ou miniers. Au cours de l'injection, le mortier de ciment ou d'un autre matériau est injecté dans le massif rocheux pour remplir les fractures et pour que le massif rocheux se comporte comme un tout entier. Contrairement à l'eau, les matériaux d'injection sont habituellement visqueux et se comportent comme des fluides non-Newtoniens. Par conséquent, les équations décrivant l'écoulement du matériau d’injection sont plus compliquées et les solutions sont assez difficiles à obtenir. Le problème est encore plus difficile à cause du fait que les fractures sont surtout distribuées de façon aléatoire et qu'il est rarement possible de définir précisément les schémas des fractures et de leur distribution. Dans cet article, un modèle numérique est proposé pour analyser le processus d'injection. Le modèle est basé sur l'approche stochastique et il peut fournir la profondeur de pénétration et la pression du fluide dues à l'écoulement du matériau d'injection, modélisé somme un fluide de Bingham, dans le massif rocheux fracturé. Des études paramétriques ont été réalisées pour étudier les effets de divers facteurs sur la profondeur de pénétration, et on a développé une formule de régression pour calculer la profondeur de pénétration. Des expériences ont été réalisées et leurs résultats ont été utilisés pour valider la présente méthode.

Mots clés : fractures stochastiques, massif rocheux fracturé, écoulement de l’injection, pénétration du matériau d'injection.

[Traduit par la Rédaction]

\section{Introduction}

Due to the presence of fractures, the strength-stiffness of a rock mass is considerably lower than the parent intact rock. On the other hand, the permeability will be higher.
Therefore, means may be required to improve the quality of the rock mass so that the strength-stiffness is increased and the permeability is reduced to satisfy the design requirements. Grouting is one of the commonly adopted methods (Baker 1985; Baker et al. 1983). Grout, which is a suspen-

Received 11 July 2001. Accepted 23 May 2002. Published on the NRC Research Press Web site at http://cgj.nrc.ca on 8 November 2002.

M.J. Yang and B. Su. College of Water Conservancy and Hydropower Engineering, Hohai University, Nanjing, China.

Z.Q. Yue ${ }^{1}$, P.K.K. Lee, and L.G. Tham. Department of Civil Engineering, The University of Hong Kong, Pokfulam Road, Hong Kong, China.

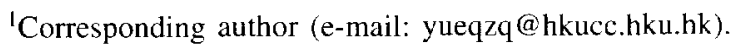


sion of cement or other materials, is injected into the rock mass to fill its fractures. Though voids are also present in the rock matrix, it is believed that their sizes are small and that they are mostly disconnected. Therefore, it is very unlikely that the grout can penetrate into them, except in very porous rocks. As only the volume of rock mass into which the grout penetrated has its properties modified, it is necessary to compute the depth of penetration in the design or analysis. The penetration depth depends on various factors, namely the properties of the grout and the grouting pressure, as well as the fracture size (width and length) and pattern in the rock mass. The grout material and grouting pressure can be controlled in the operation, and therefore, their effects on the grout depth can be easily taken into account in the design. However, the fracture characteristics are not so easy to define. It has been recognized that natural fractures in rock mass are randomly distributed (Einstein and Baecher 1983; Hudson and Priest 1979). Therefore, it is almost impossible to define the width, length, and orientation of each fracture accurately. Consequently, the depth of penetration cannot be determined exactly. Experimental methods were also used to predict the depth of penetration (Hassler et al. 1992; Wallner 1976). The applications of these results, strictly speaking, should be limited to the test conditions, and any extrapolation must be done with caution. On the other hand, theoretical approaches for the analysis of grout penetration had been developed, and most of them are based on the continuum theory (Lombardi 1985). These approaches are simple, but it may be difficult to properly model the randomness in the distribution and the width of the fractures in fractured rock mass (Zettler et al. 1995; Gustafson and Stille 1996). Assuming that the grout behaves as a Newtonian fluid, one can make use of the relations developed by various researchers for the prediction of fluid flow in fractures (He 1990; Louis 1974; Tsang 1984; Amadei and Illangasekare 1994; and Amadei et al. 1995) to predict the penetration of the grout. Because grout is a viscous fluid, and it behaves as a nonNewtonian fluid, such approach has limitations. Therefore, Amadei and Savage (2001) attempted to model the grout as a Bingham fluid and obtained an analytical solution for penetration in a single fracture. Such solutions can provide a good means for studying the mechanism of the process, but there may be difficulties in extending it to model the actual flow in fractured rock mass with a complex fracture pattern. One may, therefore, have to resort to numerical approaches such as the finite element method. Taking into account the random nature of the fractures, a stochastic approach appears to be more appropriate than the deterministic one, which is usually adopted in standard analyses.

The stochastic finite element method is an effective method for analyzing problems with uncertainties and has been widely used in mining and geotechnical engineering (Benaroya and Rehak 1988). This paper presents a stochastic finite element method for predicting the depth of penetration of the grout. Based on the Monte-Carlo method (Long et al. 1982), a procedure to generate fracture networks in rock mass is developed. These networks, although they are different in appearance, have the same statistical characteristics (orientation, number of fractures per unit area, width, etc.). Using the generated stochastic fracture networks, flow analysis can be conducted for the grout
Fig. 1. Typical fracture.

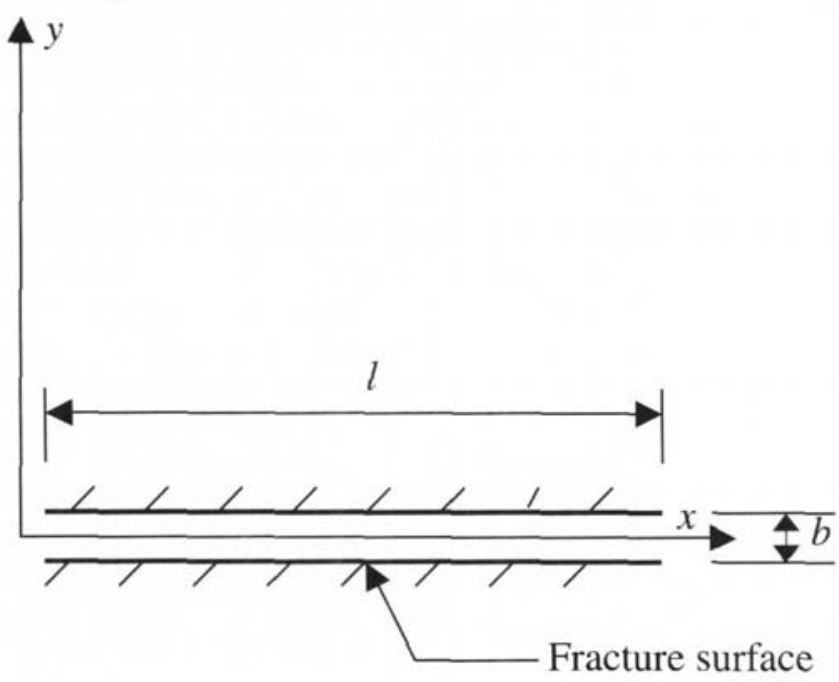

along the fractures (Elsworth 1986; Einstein and Baecher 1983; Crain and Miles 1976), and statistical analysis can be carried out to determine the probability function for the depth of grout penetration.

The results obtained by the present approach are compared with the experimental results. In general, the results are in good agreement with one another. Sensitivity analyses have been carried out, and an empirical equation, based on the results of the sensitivity analyses, is established for predicting the depth of penetration.

\section{Flow of grout along a single fracture}

Let us consider a fracture as shown in Fig. 1. The surfaces of the fracture, which are parallel, are assumed to be smooth, and the width of the fracture is $b$. Since the viscosity of the grout is usually high, it is more appropriate to model it as a Bingham fluid (Wallner 1976; and Amadei and Savage 2001). In steady state, the average velocity of flow across a section of the fracture $\left(\bar{U}_{x}\right)$ is

$$
\bar{U}_{x}=\frac{g b^{2}}{12 \eta} J+\frac{\tau_{0}^{3}}{3 \eta b \rho \gamma^{2} J^{2}}-\frac{\tau_{0} b}{4 \rho \eta}
$$

where $g$ is the acceleration due to gravity; $\tau_{0}$ is the initial shear strength of the grout; $\eta$ is the viscosity of the grout; since the viscosity changes with time, $\eta$ can be expressed in terms of the initial viscosity $\eta_{0}$, that is $\eta=\eta_{0} \exp (\alpha t)$; where $\alpha$ is a material constant;

$\gamma$ is the unit weight of the grout; and

$\rho$ is the density of the grout.

The grout pressure gradient $J$ is mathematically defined as

[2] $\quad J=\frac{\partial p}{\partial x}$

where $p$ is the grout pressure and $x$ is the distance from the left hand end of the fracture (Fig. 1).

The flow volume across the section $(q)$ is given by 
Fig. 2. The fractured network model generated using the Monte-Carlo method.

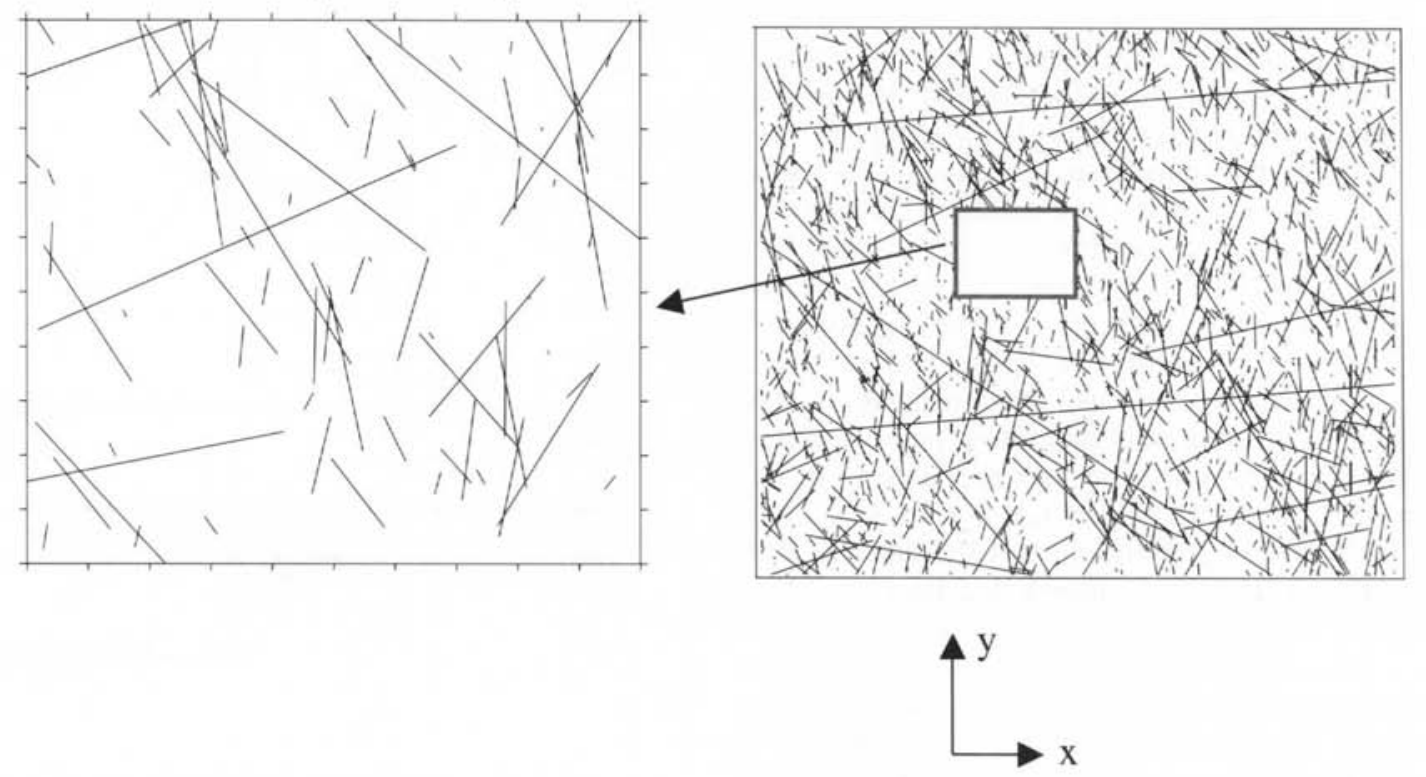

Table 1. Parameters adopted for the generation of the simulation models,

\begin{tabular}{lllll}
\hline Group & $\begin{array}{l}\text { Fracture density } \\
\left(\text { number } / \mathrm{m}^{2}\right)\end{array}$ & $\begin{array}{l}\text { Orientation (degree) } \\
(\mathrm{mean} / \mathrm{st} \mathrm{dev})\end{array}$ & $\begin{array}{l}\text { Length }(\mathrm{m}) \\
(\mathrm{mean} / \mathrm{st} \mathrm{dev})\end{array}$ & $\begin{array}{l}\text { Fracture } \\
\text { width }(\mathrm{mm})\end{array}$ \\
\hline $\mathrm{A}$ & 5 & $80 / 7$ & $0.4 / 0.05$ & 1.0 \\
$\mathrm{~B}$ & 5 & $120 / 7$ & $0.4 / 0.05$ & 1.0 \\
\hline
\end{tabular}

Note: st dev, standard deviation.

[3]

$$
q=\frac{g b^{3}}{12 \eta} J+\frac{\tau_{0}^{3}}{3 \eta \rho \gamma^{2} J^{2}}-\frac{\tau_{0} b^{2}}{4 \rho \eta}
$$

For unsteady flow, one can show that

$$
\text { [4] } \frac{\partial \bar{U}_{x}}{\partial x}=s \frac{\partial p}{\partial t}
$$

where $s$ is the storage coefficient and $t$ is the time.

Equation [4] can be solved analytically (Amadei and Savage 2001) or numerically if the boundary conditions at the two ends are given. In the next section, this approach will be extended to solve for rock mass containing multiple fractures.

\section{Flow of grout in fractured rock mass}

\section{Modeling of fractured rock mass}

Though rock mass consists of rock matrices, voids in the rock matrices, and fractures, observations show that grout mortar mainly passes through fractures in rock mass during the grouting process. Therefore, the characteristics of the fractures, including length, width, orientation, and connectivity, are key factors in determining the depth of penetration of the grout. Due to the fact that fractures are randomly distributed and their sizes vary considerably even for rock masses that are believed to be "uniform" and "homogeneous," it is almost impossible to accurately define the fracture patterns in a rock mass. A stochastic approach is therefore more appropriate for defining the fracture characteristics.
In the present study, the Monte-Carlo method (Long et al. 1982 ) is used to generate the fracture network by adopting the following assumptions: (i) every fracture is represented by a line segment; (ii) the centers of fractures are randomly and independently distributed in space; and (iii) the size and distribution of the fractures are independent of spatial location.

Based on the above assumptions, a fractured rock mass can be generated by the following procedures:

(1) A random seed is generated by using a random generation program. The seed is the midpoint of a fracture.

(2) The orientation, width, and length of the fracture are determined by using the distribution function of the respective parameters measured in the field.

(3) The coordinates of the two ends of the fracture are calculated.

(4) The above steps are repeated until a fracture network with density similar to that measured in the rock mass is attained.

Figure 2 shows a typical fractured network with two major groups of fractures generated by the above algorithm. The pertinent parameters adopted in the network generation are tabulated in Table 1, and 37 samples are generated. The permeability in each direction can be determined by applying unit head in different directions for each fractured network and carrying out flow analysis. It can be readily shown that the directional variation of the permeability can be represented by an ellipse. The minimum and maximum radii represent the minimum and maximum permeability values, respectively. The principal permeabilities, as well as the an- 
Fig. 3. Permeabilities of the simulation models. (a) Maximum permeability $\left(\mathrm{cm}^{2} / \mathrm{s}\right)$. (b) Minimum permeability $\left(\mathrm{cm}^{2} / \mathrm{s}\right)$. (c) Angle between maximum permeability and horizontal direction $\left({ }^{\circ}\right)$.

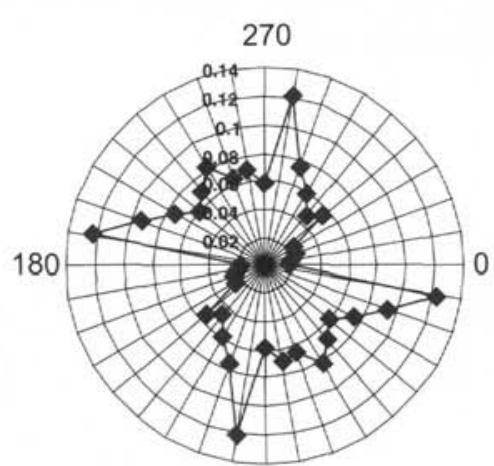

90

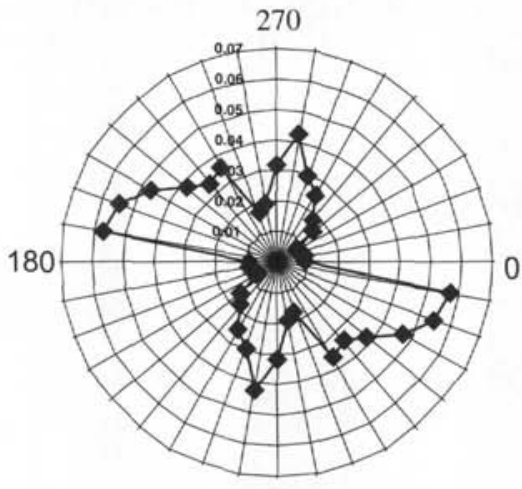

90

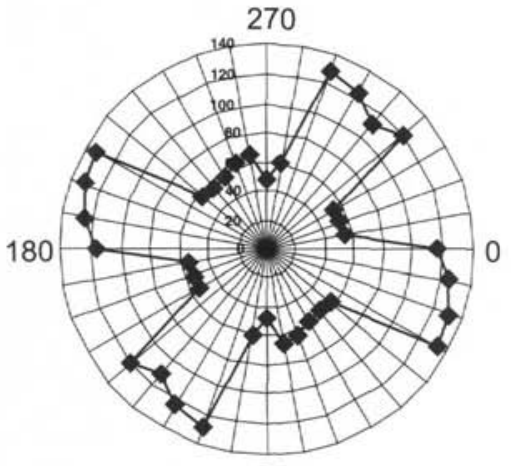

90 (a)

Fig. 4. Fractures and nodes of the numerical simulation model.

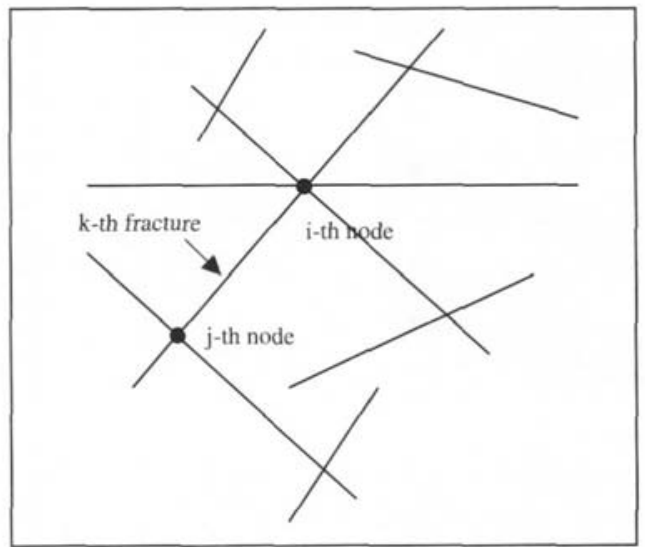

(b)

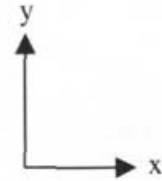

gles between the principal permeabilities and the horizontal axis, are depicted in Fig. 3.

\section{Governing equation for grout penetration}

In deriving the flow equation for a fractured rock mass, one can assume that the volume of grout flowing into a node minus the volume of grout flowing out from that node is equal to the change in the volume of grout in the node (Fig. 4). The mathematical equation thus obtained is

$$
\left(\sum_{k=1}^{M} q_{k}\right)_{i}+Q_{i}=-d_{i} \frac{\mathrm{d} H_{\mathrm{fi}}}{\mathrm{d} t} \quad(i=1,2, \ldots, N)
$$

where $q_{k}$ is the volume of grout flowing through the $k$-th fracture;

$H_{\mathrm{fi}}$ is the pressure at the $i$-th node;

$d_{i}$ is $\frac{s_{i}}{2} \sum_{k=1}^{M} b_{k} l_{k}$;

$b_{k}$ and $l_{k}$ are the width and length of the $k$-th fracture, respectively;

$s_{i}$ is the elastic storage at the $i$-th node;

$Q_{i}$ is the volume of grout flowing into or out of the $i$-th node; and
$M$ is the number of fractures passing through the $i$-th node.

Substituting $q_{k}$ from eq. [3] into eq. [5], we have

$$
\left(\sum_{k=1}^{M} \beta_{k} J_{k}\right)_{i}+Q_{i}=-d_{i} \frac{\mathrm{d} H_{\mathrm{f} i}}{\mathrm{~d} t} \quad(i=1,2, \ldots, N)
$$

In the above equation,

$$
\beta_{k}=\frac{g b_{k}^{3}}{12 \eta}+\frac{\tau_{0}^{3}}{3 \eta \rho \gamma^{2} J_{k}^{3}}-\frac{\tau_{0} b_{k}^{2}}{4 \rho \eta J_{k}}
$$

and $J_{k}$ is the pressure gradient of the $k$-th fracture.

As flow can only occur between fractures that are connected, we can show readily that

$$
\begin{aligned}
G\left(\frac{g b_{k}^{3}}{12 \eta}+\frac{\tau_{0}^{3}}{3 \eta \rho \gamma^{2} J_{k}^{3}}-\frac{\tau_{0} b_{k}^{2}}{4 \rho \eta J_{k}}\right) J_{k} G^{\mathrm{T}}+Q_{i} & \\
& =S \times G \times \theta_{3} \times \theta_{4} \frac{\left(H_{\mathrm{f} i}-H_{\mathrm{fi}}^{\mathrm{o}}\right)}{2 \Delta t}
\end{aligned}
$$

where $G$ is the connection matrix, and $G^{\mathrm{T}}$ is the transpose matrix of $G$. If the $i$-th node is connected to the $j$-th node by the $k$-th fracture, then $G(i, j)=1$ when the flow direction is from $i$ to $j$. When the flow direction is from $j$ to $i, G(i, j)=-1$. If the $i$-th and $j$-th nodes are not connected, $G(i, j)=0$. The elastic storage matrix of all nodes, $S$, is equal to $\left(s_{1}, s_{2}, \ldots, s_{\mathrm{n}}\right)^{\mathrm{T}} ; \Delta t$ is the time step; and $\theta_{3}$ and $\theta_{4}$ are the vectors containing the width and length of each fracture, respectively.

Furthermore, it is not difficult to show that

$$
\begin{array}{r}
G \frac{\left(\frac{\gamma \theta_{3}^{3}}{12 \eta}\right) H_{\mathrm{f} i}}{\theta_{4}} G^{\mathrm{T}}+G \frac{\tau_{0}^{3}}{3 \eta \gamma^{2}} \frac{H_{\mathrm{fi}}^{-2}}{\theta_{4}^{-2}} G^{\mathrm{T}}-G \frac{\tau_{0} \theta_{3}^{2}}{4 \eta} G^{\mathrm{T}}+Q_{i} \\
=\rho S \times G \times \theta_{3} \times \theta_{4} \frac{\left(H_{\mathrm{f} i}-H_{\mathrm{f} i}^{\mathrm{o}}\right)}{2 \Delta t}
\end{array}
$$

As the spacing and orientation of the fractures, $N, \theta_{3}$, and $\theta_{4}$ are random variables, $\left(G \frac{\gamma \theta_{3}^{3}}{12 \eta \theta_{4}} G^{\mathrm{T}}\right), G \frac{\tau_{0} \theta_{4}^{2}}{3 \eta \gamma^{2}} G^{\mathrm{T}}, G \frac{\tau_{0} \theta_{3}^{2}}{4 \eta} G^{\mathrm{T}}$, 
Fig. 5. The experimental setup.

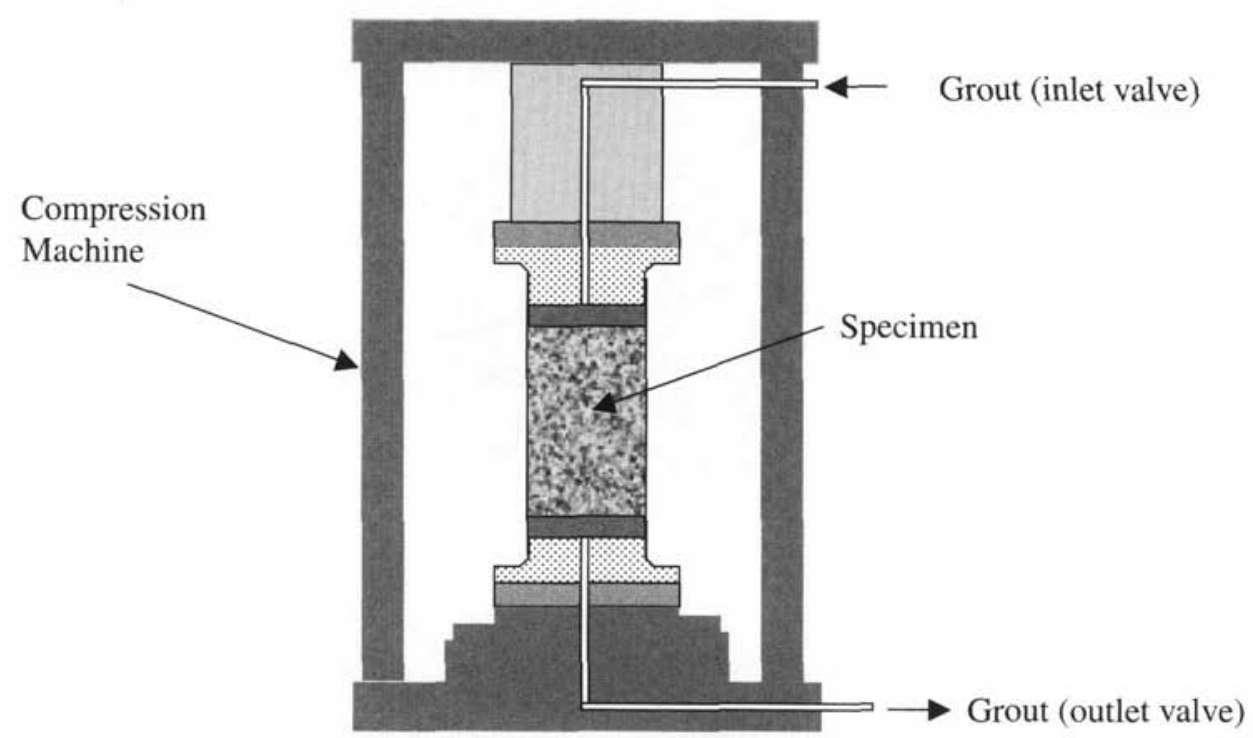

Fig. 6. Grout intake for the single fracture models. Grouting pressure was $0.2 \mathrm{MPa}$ in all cases.

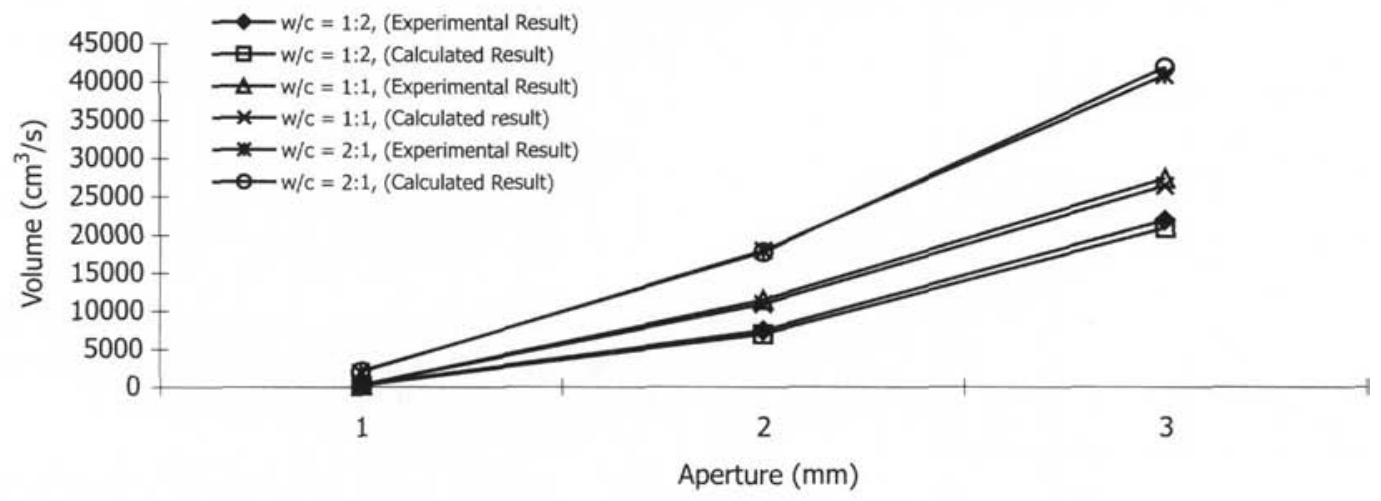

Fig. 7. The fracture patterns of multiple fracture models.

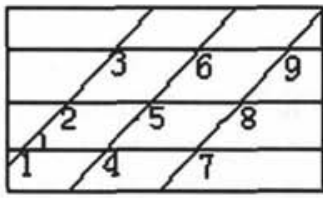

Cross angle $=30^{\circ}$

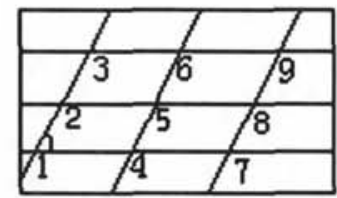

Cross angle $=60^{\circ}$

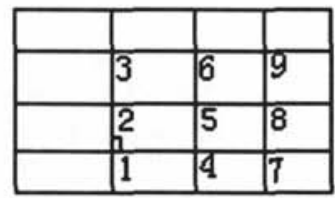

Cross angle $=90^{\circ}$
Table 2. Schedule of the experimental study for multiple fracture model.

\begin{tabular}{llll}
\hline Case & Width $(\mathrm{mm})$ & Cross angle $\left({ }^{\circ}\right)$ & Water-cement ratio \\
\hline 1 & $1 \sim 1$ & 30 & $2: 1$ \\
2 & $1 \sim 1$ & 60 & $1: 1$ \\
3 & $1 \sim 1$ & 90 & $1: 2$ \\
4 & $1 \sim 2$ & 30 & $1: 1$ \\
5 & $1 \sim 2$ & 60 & $1: 2$ \\
6 & $1 \sim 2$ & 90 & $2: 1$ \\
7 & $1 \sim 4$ & 30 & $1: 2$ \\
8 & $1 \sim 4$ & 60 & $2: 1$ \\
9 & $1 \sim 4$ & 90 & $1: 1$ \\
\hline
\end{tabular}

and $S \times G \times \theta_{3} \times \theta_{4}$ are random matrices. Therefore, it is necessary to determine the sample size to get statistically representative results. The sample size will depend on the mean values and the deviations of the random variables, and it can be determined by using the limited distribution theorem (Speigel 1992). A detailed discussion on the determination of the sample size is given in Appendix A.

Having the simulated models generated, the distribution of the pressure can be computed accordingly. The penetration depth can be determined by comparing $H_{\mathrm{f} i}$ and $H_{\mathrm{f} i}^{\mathrm{o}}\left(H_{\mathrm{f} i}^{\mathrm{o}}\right.$ is the initial pressure head). One can assume that the grout has reached the $i$-th node if $H_{\mathrm{fi}}$ is greater than $H_{\mathrm{fi}}^{\circ}$ of that node. From the results, the probability function for the depth of grout penetration can be determined accordingly. 


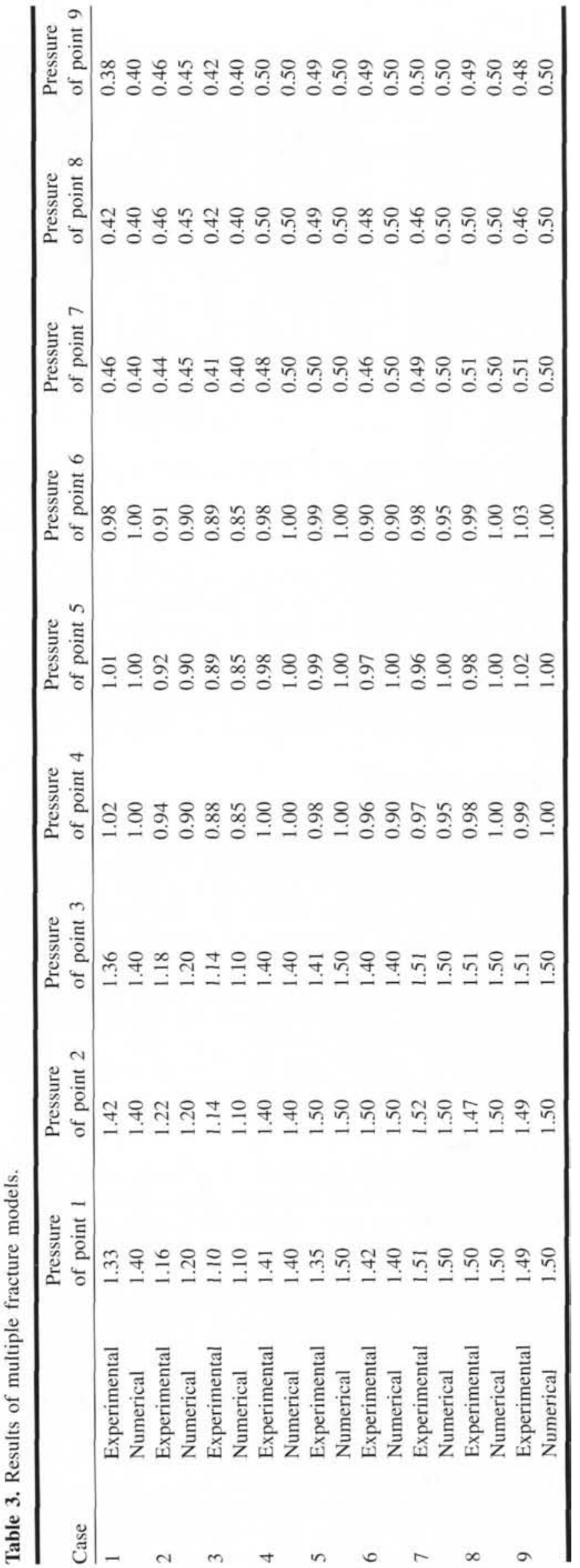

Fig. 8. A simulation model generated using the parameters given in Table 1.

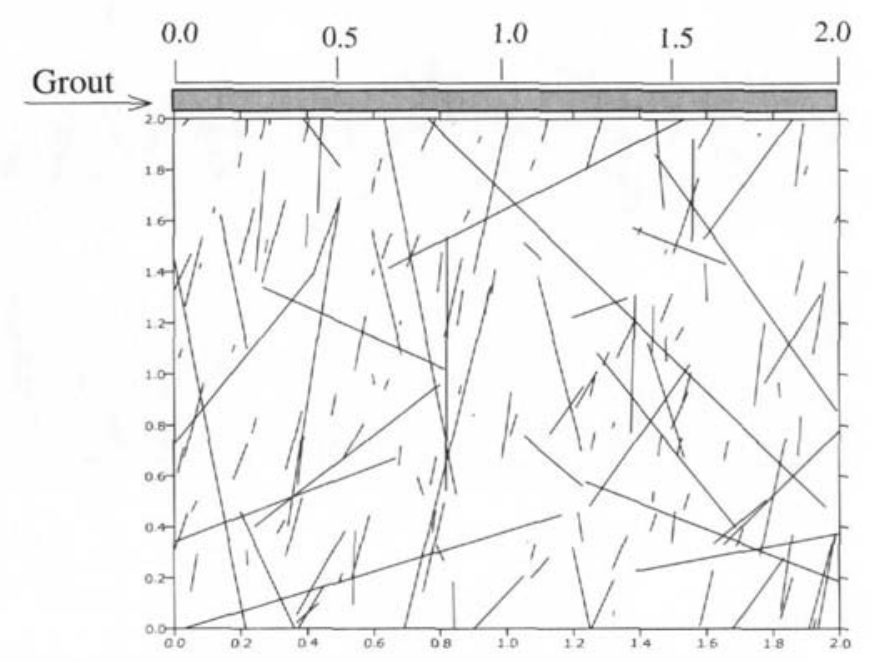

It must be pointed out that $Q_{i}$, which is the source strength, is assumed to be a determinate variable in the analysis.

\section{Validation of the numerical model}

To assess the accuracy of the numerical model, a number of tests were carried out in the laboratory using cement models to study the flow of grout in a single fracture. Figure 5 shows the setup of the tests. By varying the width, the grout pressure, and the water-cement (w/c) content of the grouts, a series of tests were carried out, and the results were compared with the numerical model. The comparison between the experimental and numerical flow volume, as shown in Fig. 6, indicates that the results of the present approach agree fairly well with the experimental ones.

Further tests were carried out to validate the model in the cases of multiple fractures arranged in different patterns. Three different patterns of fractures (Fig. 7) were simulated. The widths of the fractures varied from 1 to $4 \mathrm{~mm}$ so that fractures of different widths were simulated. The size of the models was $500 \mathrm{~mm} \times 300 \mathrm{~mm}$. The fractures were formed by placing the steel plates into the mould according to the required spacings and orientations. The steel plates were removed carefully after the setting of the cement. As the grout was injected into the model, the pressure along the grouting penetration path was measured. A series of tests (Table 2) were conducted and the results are tabulated in Table 3.

The results obtained by using the present numerical model are also given in Table 3. The parameters used in the analysis are given as the following, $\eta_{0}=34 \mathrm{mPa} \cdot \mathrm{s}, \tau_{0}=14 \mathrm{~Pa}$, $\rho=1.4 \times 10^{3} \mathrm{~kg} / \mathrm{m}^{3}$, and $s_{i}=0.3,(i=1,2, \ldots n)$. In general, the numerical results are in good agreement with the experimental ones.

\section{Grout penetration in fractured rock mass}

Based on the parameters given in Table 1, numerical simulations were conducted for fractured rock masses. A typical model is depicted in Fig. 8. The grout was injected from the top surface (Fig. 8). The grouting pressure was $2.0 \mathrm{MPa}$. The 
Fig. 9. Depth of grout penetration at different times for the sample shown in Fig. 8.

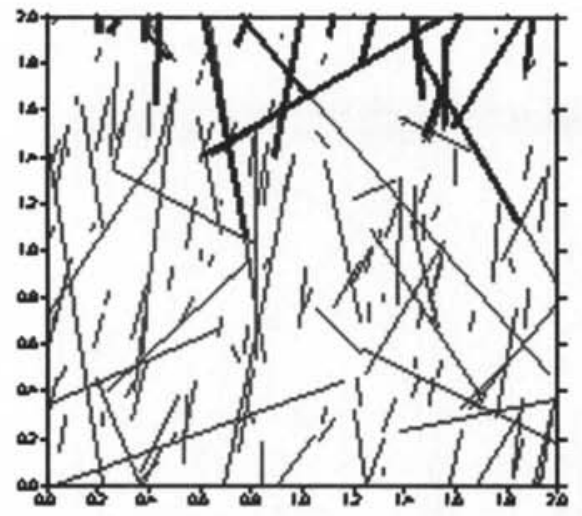

$$
t_{1}=100 \mathrm{~s}
$$

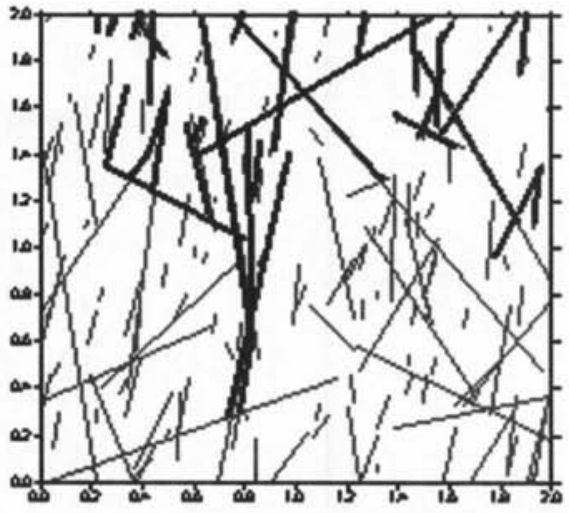

$t_{2}=200 \mathrm{~s}$

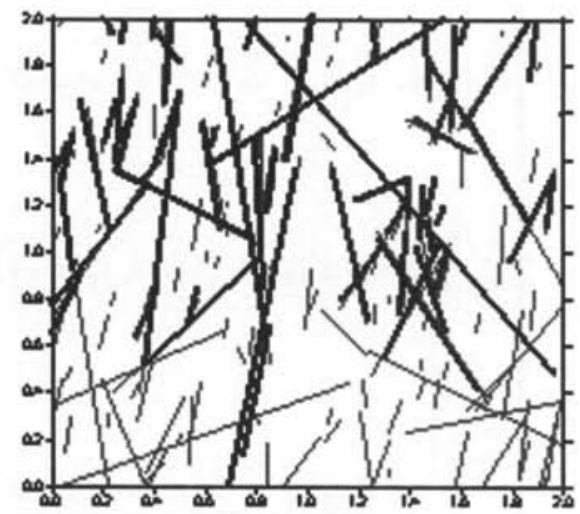

$t_{3}=500 \mathrm{~s}$
Fig. 10. Variation of grout intake $\left(\mathrm{cm}^{3} / \mathrm{s}\right)$ with time.

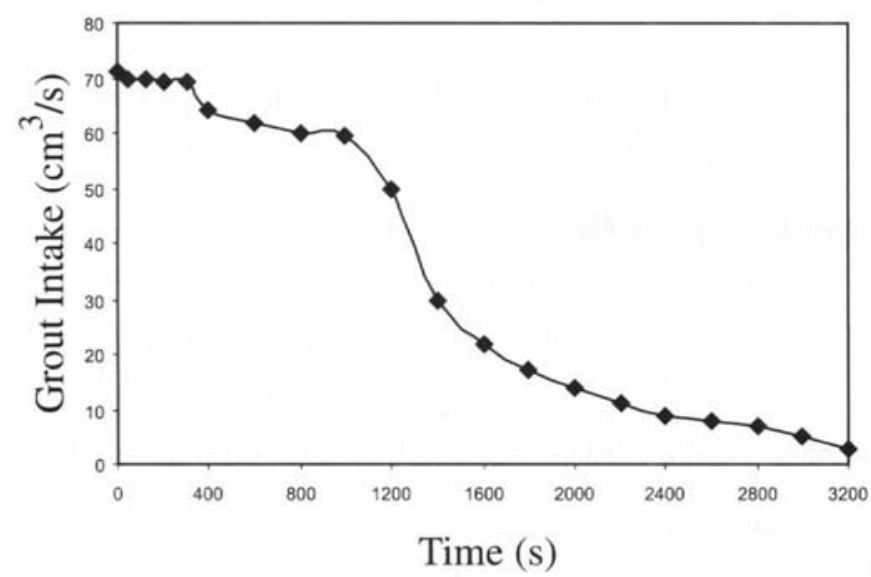

w/c ratio of the grout was 0.5 . The viscosity and initial shear strength of the grout were $3.4 \mathrm{mPa} \cdot \mathrm{s}$ and $56 \mathrm{~Pa}$, respectively.

Figure 9 shows the depth of grout penetration at different times. The results indicate that the depth of grout penetration along a particular fracture depends very much on its connectivity. Furthermore, the grout intake tends to reduce gradually during the grouting process (Fig. 10). Such results are not unexpected because the number of unfilled cracks will be reduced as the cracks are being filled up.

Figure 11 shows the results for two different simulation models. It must be pointed out that the characteristics of the cracks are statistically similar. However, the penetration patterns are different. The results further confirm the nondeterministic nature of the process.

To demonstrate the effects of the various parameters on the depth of penetration, sensitivity studies were carried out. The parameters include (i) the characteristics of the fracture (density, width, orientation, and length); (ii) the grout pressure; and (iii) the material properties of the grout (initial shear strength and viscosity).

\section{Fracture density}

In the analysis, three cases with different fracture densities were considered, that is, $1.5,2.0$, and 2.5 fractures $/ \mathrm{m}^{2}$. Other parameters remained unchanged. The probabilities of the depth of penetration are plotted in Fig. 12a. The results indicate that the mean depth (depth of penetration) increases as the density increases.

\section{Fracture width}

Another study was conducted by varying the width of the fractures $(1.0,2.0$, and $3.0 \mathrm{~mm})$. The results are plotted in Fig. $12 b$. As expected, the depth of penetration increases as the width increases. Furthermore, analyses were also carried out by varying the standard deviation of the width from 0.33 to $0.75 \mathrm{~mm}$. The results (Fig. 12c) show that the depth of penetration increases as the standard deviation increases.

\section{Fracture orientation}

As grout will be flowing along the fractures, the direction of the fractures is also an important parameter. Varying the mean value of fracture direction from 40 to $80^{\circ}$, a series of analyses was carried out to determine the depth of penetration. The standard deviation was $10^{\circ}$. The results are depicted in Fig. 12d. Increasing the standard deviation is equivalent to increasing the randomness of the orientation. Therefore, another analysis was carried out by assuming the standard deviation to be $90^{\circ}$ to obtain the upper bound solution for random orientated fractures. The results are given in Fig. 12e. One can note that the depth of penetration increases as the standard deviation increases.

\section{Fracture length}

Figure $12 f$ shows the results of the analyses carried out by varying the length of the fractures. Three different lengths $(1.0,2.0$, and $3.0 \mathrm{~m})$ were studied. The results indicate that it will be easier for the grout to penetrate if the fracture length is longer. Furthermore, the depth of penetration is also more uniform. By varying the standard deviation $(0.1$ to 0.5 , then 1.0 ), one can study the effect of the standard deviation of the fracture length. The results given in Fig. $12 \mathrm{~g}$ are for the case with mean length equal to $2.0 \mathrm{~m}$. It is obvious that the depth of penetration will become less uniform as the standard deviation increases.

\section{Grout pressure}

Grout pressure is another factor that will affect the depth of penetration. Considering three different cases with grout pressures $2.0,3.0$, and $4.0 \mathrm{MPa}$, analyses were carried out 
Fig. 11. Comparison of depth of grout penetration for two different simulation models (time is equal to $500 \mathrm{~s}$ ).

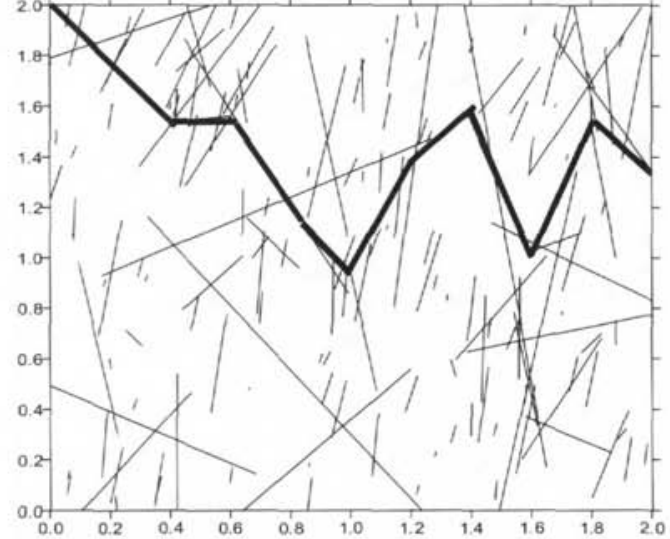

Table 4. Regression relationships for the depth of grout penetration.

\begin{tabular}{ll}
\hline Factor & Regression relationship \\
\hline Density & $y=0.2 x^{2}+1.3 x-1.2$ \\
Mean value of aperture & $y=-0.045 x^{2}+0.255 x+0.59$ \\
Deviation of aperture & $y=0.0123 x^{2}-0.3704 x+0.9209$ \\
Mean value of orientation & $y=0.08375 x-1.75$ \\
Deviation of orientation & $y=0.0063 x+0.16$ \\
Mean value of trace length & $y=0.04 x^{2}-0.05 x+0.09$ \\
Deviation of trace length & $y=0.017 x^{2}+0.015 x+0.1483$ \\
Grouting pressure & $y=0.005 x^{2}-0.005 x+0.29$ \\
Viscosity & $y=0.0175 x^{2}-0.0719 x+0.018$ \\
Initial shear strength & $y=-0.00107 x+0.1933$ \\
\hline
\end{tabular}

and the results are shown in Fig. $12 h$. As expected, the depth of penetration increases as the pressure increases.

\section{Properties of the grout}

The flow of the grout will also be affected by the initial shear strength and the viscosity of the grout. To study their effect, two series of analyses were carried out. In the first series, three different coefficients of viscosity $(0.034,0.34$ and $3.4 \mathrm{mPa} \cdot \mathrm{s}$ ) were considered and in the second series the initial shear strengths were varied $(14,28$, and $56 \mathrm{~Pa})$. The results are given in Figs. $12 i$ and $12 j$, respectively. It appears that the effect of viscosity is more significant than the effect of the initial shear strength, which was anticipated.

\section{Semi-empirical relation for the prediction of depth of penetration}

Based on the results obtained in the previous section, regression relationships between the various factors and the depth of grout penetration can be derived. The relationships are given in Table 4 . It must be pointed out that the relationships are determined for the cumulative probability of $85 \%$.

The above relationships can be used to predict the effect on the depth of penetration for each factor. However, these factors will be influencing the depth interactively in the real situation. To predict the penetration depth, it is necessary to combine the effects of these factors. A method for combining the effects of the various factors was developed. One can first compute the weight of each factor to quantify the rela-

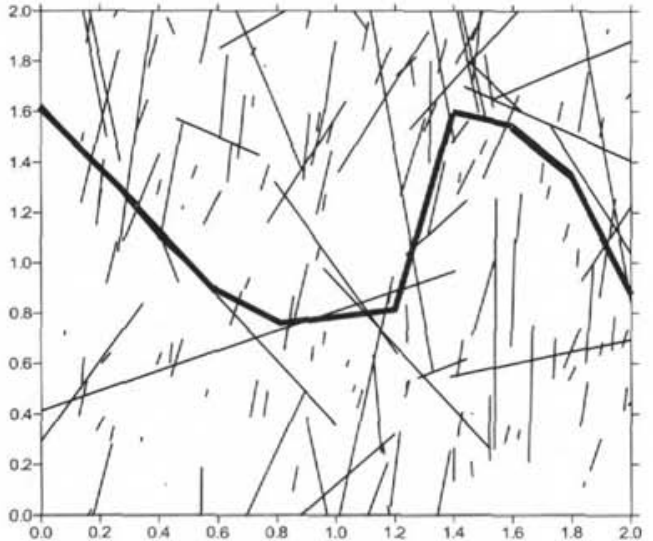

Table 5. Degree of sensitivity.

\begin{tabular}{ll}
\hline Factor & Sensitivity degree \\
\hline Density & 1.714 \\
Mean aperture & 0.167 \\
Deviation of aperture distribution & 0.448 \\
Mean orientation & 1.35 \\
Deviation of orientation distribution & 0.42 \\
Mean fracture length & 1.245 \\
Deviation of fracture distribution & 0.11 \\
Grouting pressure & 0.25 \\
Viscosity & 0.10 \\
Initial shear strength & 0.06 \\
\hline
\end{tabular}

tive effect of the factor. This can be achieved by considering the degree of sensitivity, which can be defined as follows :

$$
S_{\mathrm{K}}\left(A_{\mathrm{K}}\right)=\frac{1}{m} \sum_{i=1}^{m}\left|\frac{\Delta P_{i}}{\Delta A_{\mathrm{K}}}\right| \frac{A_{\mathrm{K}}}{P_{i}}
$$

where $S_{\mathrm{K}}\left(A_{\mathrm{K}}\right)$ is the degree of sensitivity; $A_{\mathrm{K}}$ is the factor under consideration; $\Delta A_{K}$ is the relative deviation of the factors; $\Delta P$ is the system response deviation due to the change of factors; $P$ is the system response; and $m$ is the level number of factors.

Based on the above formula and the results reported in the previous section, the degrees of sensitivity for the various factors can be derived, and they are given in Table 5 .

Combining the degree of sensitivity and the regression relation, one can obtain the relationship for the prediction of the depth of grout penetration

$$
\begin{array}{rl}
R=6 & 834 \times 10^{-3} D^{1.201} B^{0.524} \delta B^{-0.969} \\
& \times \theta^{0.196} \delta \theta^{0.272} L^{1.489} \delta L^{0.101} p^{0.617} \tau_{0}^{-0.325} \eta_{0}^{-0.109}
\end{array}
$$

where $R$ is the depth of penetration;

$D$ is the fracture density;

$B$ is the mean width of the fractures;

$\delta B$ is the standard deviation of the width of the fractures;

$\theta$ is the mean angle of inclination of the fractures to the horizontal axis;

$\delta \theta$ is the standard deviation of the angle of inclination of the fractures to the horizontal axis; 
Fig. 12. Results of the parametric study.

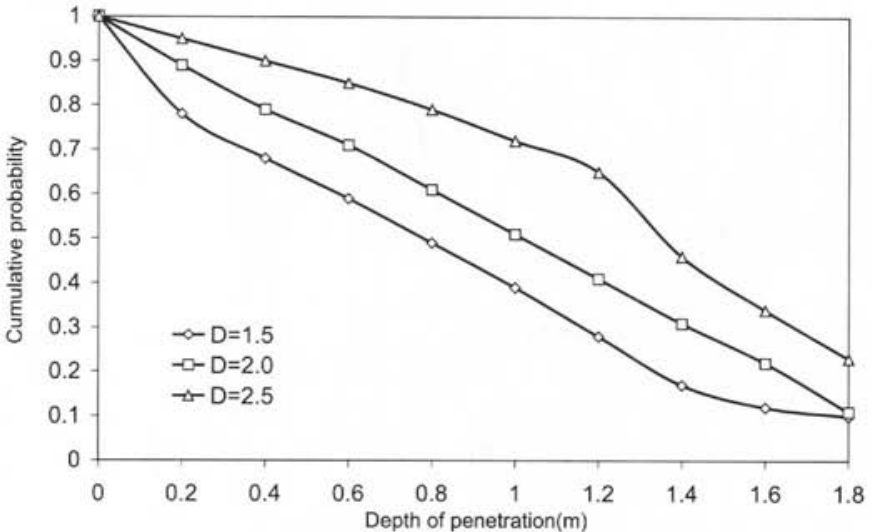

(a) Fracture density

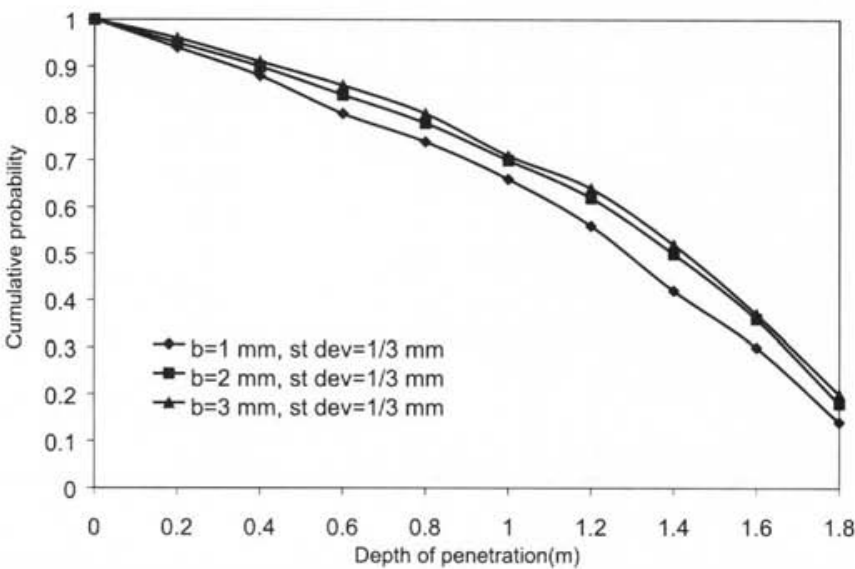

(b) Fracture width

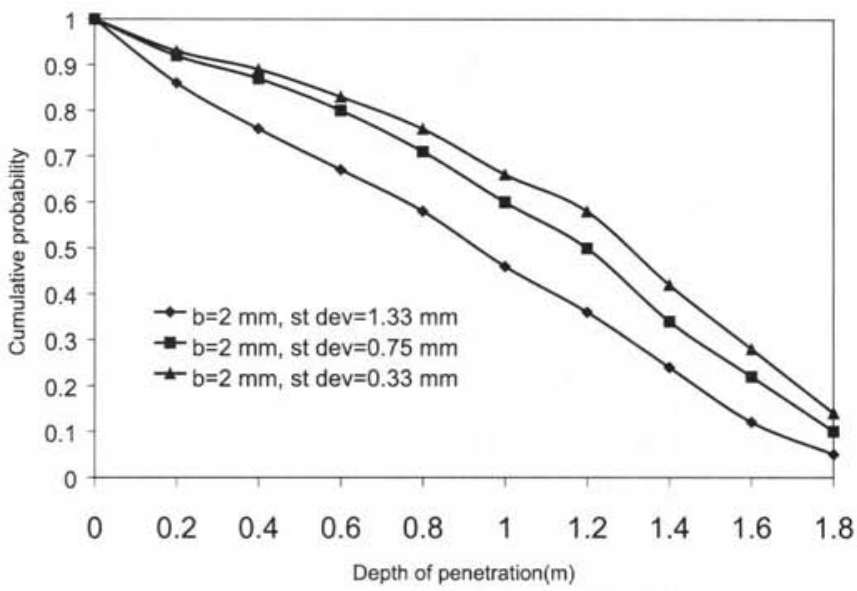

(c) Fracture width

$L$ is the mean length of the fractures;

$\delta L$ is the standard deviation of the length of the fractures;

$p$ is the grouting pressure;

$\tau_{0}$ is the initial shear strength of the grout; and

$\eta_{0}$ is the inital viscosity of the grout.

It must be pointed out that the above equation should only be applied to rock mass with the fracture characteristics defined in Table 1. However, such an approach can be applied

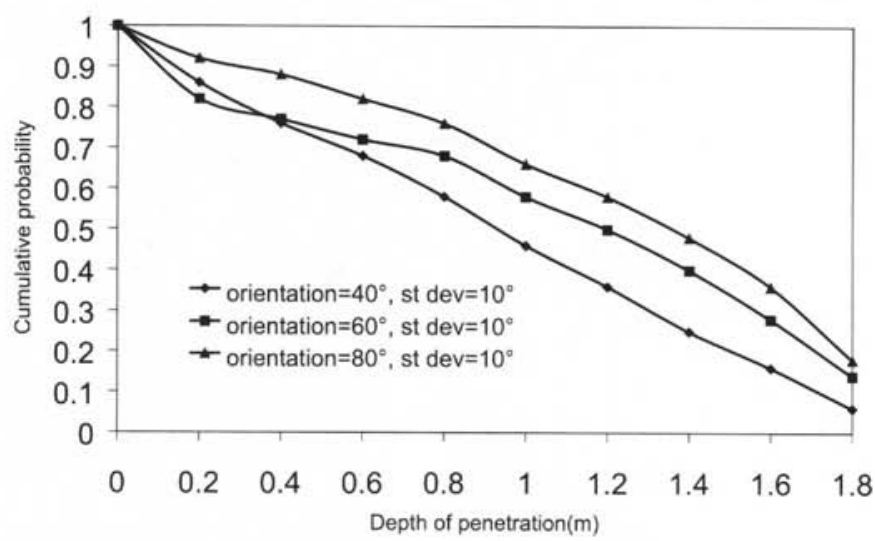

(d) Fracture orientation

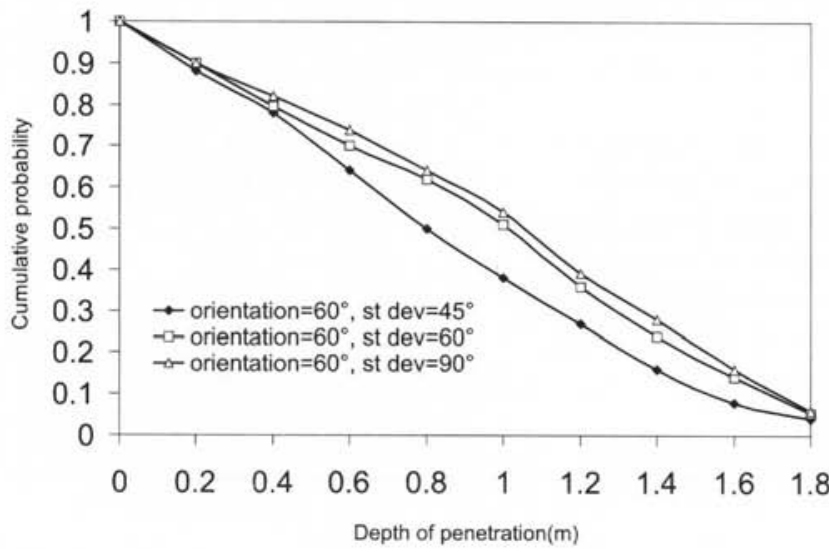

(e) Fracture orientation

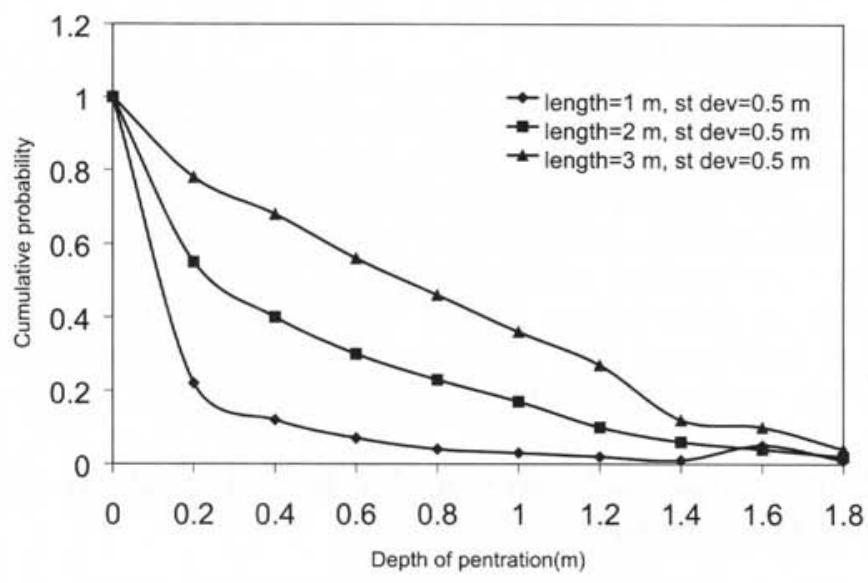

(f) Fracture length

to obtain the equation for prediction of the depth of grout penetration after the sensitivity analysis.

\section{Summary and conclusions}

Assuming that the grout behaves as a Bingham fluid, a numerical model is developed to predict the flow of grout in fractured rock masses. Experimental studies were carried out to validate the model, and the results show that the numeri- 


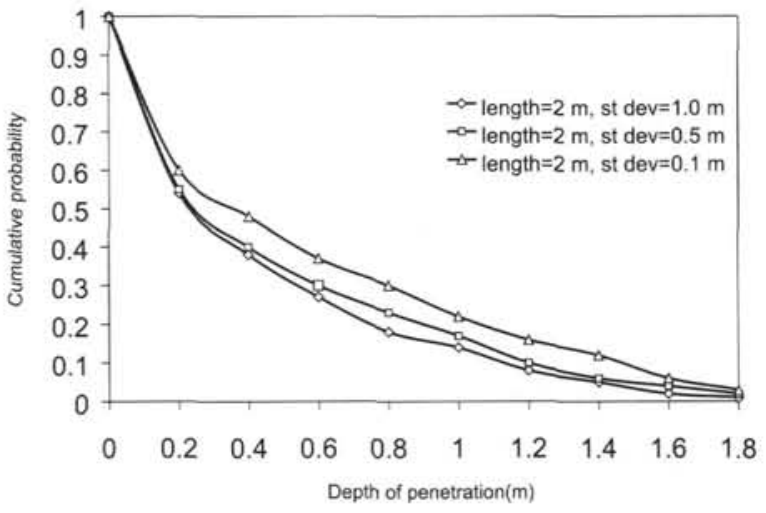

(g) Fracture length

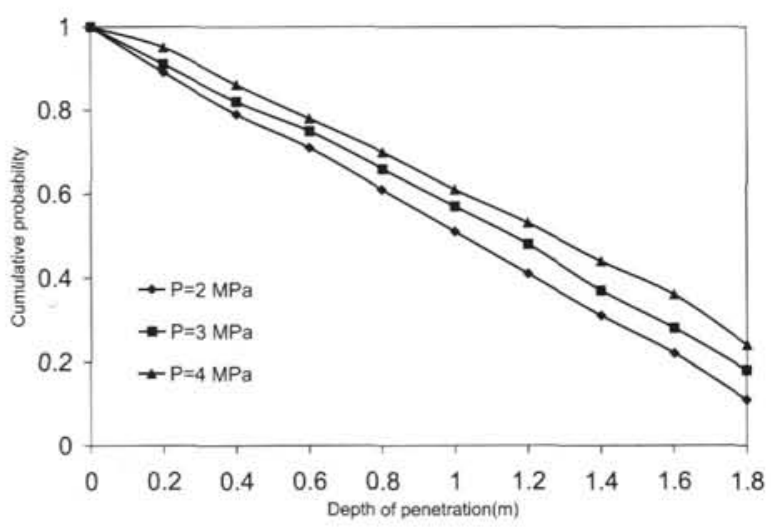

(h) Grout pressure

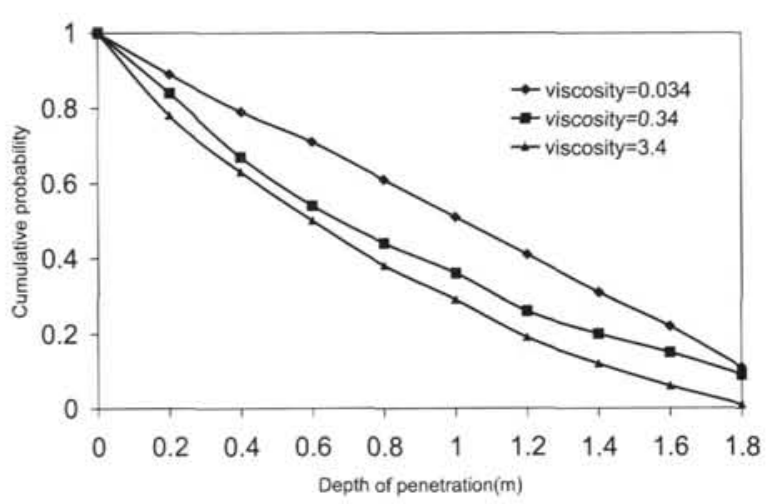

(i) Viscosity

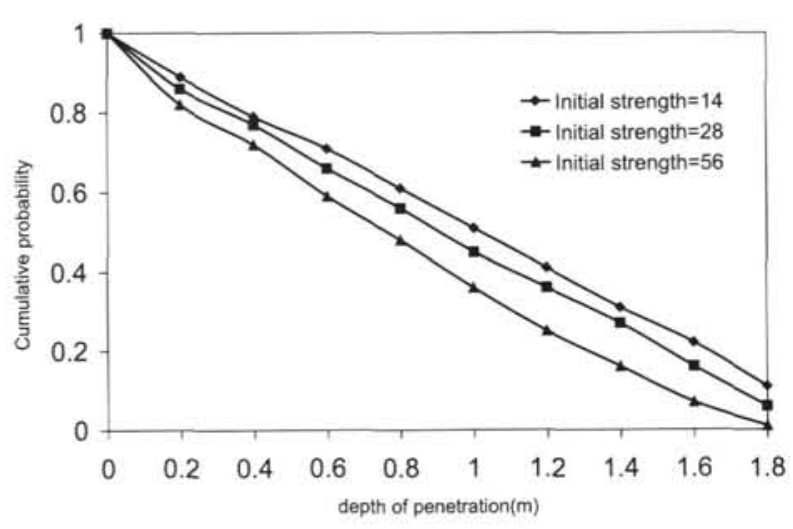

(j) Initial strength
Fig. 12. concluded.

cal model can fairly well predict the depth of grout penetration. Taking into account the fact that the fracture patterns cannot be easily defined, the Monte-Carlo approach is used to generate simulated models with statistically similar fractured patterns. Based on the numerical results, a method for computing the depth of the grout penetration is developed. It must be pointed out that the present method has considered only smooth fractures, and therefore, rugosity and tortuosity were not considered.

\section{Acknowledgements}

The study is financially supported by the Research Grants Council of Hong Kong and the Hong Kong Jockey Club Charities Trust. The authors would also like to thank the two peer reviewers, Dr. Dennis E. Becker and an Associate Editor for their valuable comments and suggestions, which greatly improved the presentation of the manuscript.

\section{References}

Amadei, B., and Illangasekare, T. 1994. A mathematical model for flow and solute transport in non-homogeneous rock fractures. International Journal of Rock Mechanics and Mining Sciences, 31(2): 719-731.

Amadei, B., and Savage, W.Z. 2001. An analytical solution for transient flow of Bingham viscoplastic materials in rock fractures. International Journal of Rock Mechanics and Mining Sciences, 38(2): 285-296.

Amadei, B., Carlier, J.F., and Illangasekare, T. 1995. Effect of turbulence on fracture flow and advective transport of solute. International Journal of Rock Mechanics and Mining Sciences, 32(4): 343-356.

Baker, W.H. 1985. Embankment foundation densification by compact grouting: Issues in dam grouting. In Proceedings of the Geotechnical Engineering Division, ASCE, 10 April 1985, Denver, CO. pp. 104-122.

Baker, W.H., Cording, E.J,, and MacPherson, H.H. 1983. Compaction grouting to control ground movements during tunneling. In Underground space, Pergamon Press, NY. pp. 205-212.

Benaroya, H., and Rehak, M. 1988. Finite element methods in probabilistic structural analysis: a selective review. Applied Mechanics Reviews, 41(5): 201-213.

Crain, K., and Miles, R.E. 1976. Monte Carlo estimates of the distributions of the random polygons determined by random lines in a plane. Journal of Statistical Computation and Simulation, 4 : $293-325$.

Einstein, H.H., and Baecher, G.B. 1983. Probabilistic and statistical methods in engineering geology, specific methods and examples, Part 1: Exploration. Rock Mechanics and Rock Engineering, 16(1): 39-72.

Elsworth, D. 1986. A model to evaluate the transient hydraulic response of three dimension sparsely fractured rock masses. Water Resources Research, 22: 1809-1819.

Gustafson, G., and Stille, H. 1996. Prediction of groutability from grout properties and hydrological data. Tunnelling and Underground Space Technology, 11: 325-332.

Hassler, L., Hakansson, U., and Stille, H. 1992. Computersimulated flow of grouts in jointed rock. Tunnelling and Underground Space Technology, 7: 441-446. 
He, X.R. 1990. Grouting reinforcement and blocking water. Northeastern University Press, China. (In Chinese.)

Hudson, J.A., and Priest, S.D. 1979. Discontinuities and rock mass geometry. International Journal of Rock Mechanics and Mining Sciences, 16(6): 339-362.

Lombardi, G. 1985. The role of the cohesion on cement grouting of rock. In Proceedings of the 15th Congress on Large Dams, Lausanne, International Commission on Large Dams (ICOLD), pp. 235-261.

Long, J.C.S., Remer, J.S., Wilson, C.R., and Witherspoon, P.A. 1982. Porous media equivalents for networks of discontinuous fractures. Water Resources Research, 18(3): 645-658.

Louis, C. 1974. Rock hydraulics. In Rock mechanics. Edited by L. Muller. Springer, NY.

Speigel, M.R. 1992. Theory and problems of probability and statistics. McGraw Hill, NY.

Tsang, Y.W. 1984. The effect of tortuosity on fluid flow through a single fracture. Water Resources Research, 20(9): 1209-1215.

Wallner, M. 1976. Propagation of sedimentation stable cement pastes in jointed rock. Rock Mechanics and Waterways Construction, 2: 132-136.

Zettler, A.H., Poisel, R., and Stadler, G. 1995. Behavior of viscoplastic fluid in narrow joints with non-parallel investigation of a rock grouting process. In Mechanics of jointed and faulted rock, A.A. Balkema, Rotterdam. pp. $450-458$.

\section{Appendix A}

Since the spacing, orientation, length, and width of the fractures are random variables, it is necessary to generate a sufficient number of simulation models so that statistical representative results can be obtained.

We can note that four matrices of eq. [8], namely $\left(G \frac{\gamma \theta_{3}^{3}}{12 \eta \theta_{4}} G^{\mathrm{T}}\right), G \frac{\tau_{0}^{3} \theta_{4}^{2}}{3 \eta \gamma^{2}} G^{\mathrm{T}}, G \frac{\tau_{0} \theta_{3}^{2}}{4 \eta} G^{\mathrm{T}}$, and $S \times G \times \theta_{3} \times \theta_{4}$, depend on random variables. Let us define

[A1] $f(x)=\frac{\gamma \theta_{3}^{3}}{12 \eta \theta_{4}}=A \theta_{3}^{3} \theta_{4}^{-1}$ where $A=\frac{\gamma}{12 \eta}$

Expanding $f(x)$ and assuming that the deviation of the random variable is small, we can show that

$$
\begin{aligned}
f(x)=A \theta_{3}^{3} \theta_{4}^{-1}=A \bar{\theta}_{3}^{3} \bar{\theta}_{4}^{-1}+A\left(3 \bar{\theta}_{3}^{2}\left(\theta_{3}-\bar{\theta}_{3}\right) \bar{\theta}_{4}^{-1}\right. & \\
& -\bar{\theta}_{3}^{3} \bar{\theta}_{4}^{-2}\left(\theta_{4}-\bar{\theta}_{4}\right)
\end{aligned}
$$

We can define the mean value of $f(x)$

[A3] $E(f(x))=E\left(A \theta_{3}^{3} \theta_{4}^{-1}\right)=A \bar{\theta}_{3}^{3} \bar{\theta}_{4}^{-1}$

and its variance is

$$
\begin{array}{r}
\text { [A4] } \left.D(f(x))=D\left(A \theta_{3}^{3} \theta_{4}^{-1}\right)=D\left(A 3 \bar{\theta}_{3}^{2} \delta \theta_{3} \bar{\theta}_{4}^{-1}-\bar{\theta}_{3}^{3} \bar{\theta}_{4}^{-2} \delta \theta_{4}\right)\right) \\
=A^{2}\left(\left(3 \bar{\theta}_{3}^{2} \bar{\theta}_{4}^{-1}\right)^{2} D\left(\theta_{3}\right)-\left(\bar{\theta}_{3}^{3} \bar{\theta}_{4}^{-2}\right)^{2} D\left(\theta_{4}\right)\right)
\end{array}
$$

In the above formula, $D\left(\theta_{3}\right)$ and $D\left(\theta_{4}\right)$ are the variance of $\theta_{3}$ and $\theta_{4}$, respectively.

Based on the limited distribution theorem (Speigel 1992), we can show that

[A5] $\frac{f(x)-E(f(x))}{D(f(x)) / \sqrt{n}} \sim N(0,1)$

For a confidence level of $95 \%$, the minimum sample size required is

[A6] $\quad n_{1} \geq \frac{1.96^{2} D(f(x))}{0.05^{2}}$

where $n_{1}$ is the number of models. As the variance of $f(x)$ can be computed using eq. [A4], one can easily calculate $n_{1}$.

A similar approach can be used to determine the minimum sample size required for the remaining three terms, that is $G \frac{\tau_{0}^{3} \theta_{4}^{2}}{3 \eta \gamma^{2}} G^{\mathrm{T}}, G \frac{\tau_{0} \theta_{3}^{2}}{4 \eta} G^{\mathrm{T}}$, and $S \times G \times \theta_{3} \times \theta_{4}$. For the parameters given in Table 1, one can show that the minimum sample size required for the four terms are 1783, 1168, 1634 , and 1430 , respectively. Therefore, one will require at least 1783 simulation models. In the analysis, 1800 simulation models were generated. 